\title{
Conference on Fruit Juices and Syrups
}

\begin{abstract}
A
CONFERENCE and working demonstration on pure fruit juices and syrups was held at the University of Bristol Research Station (which is associated with the Ministry of Agriculture and Fisheries) on March 23. More than a hundred visitors attended the conference. The conference comprised four papers dealing with various aspects of fruit products developments. Prof. B. T. P. Barker, the director, referred to the association of the Long Ashton Station with fruit products research since its inception as a Cider Institute. The production of apple jelly and the pulping of soft fruits by the cold sulphur dioxide method were contributions made by the Station during the Great War period, and in more recent years the Station had commenced a comprehensive investigation into the whole question of the utilization of surfilus and low grade fruit.

World developments in fruit juices were discussed by Mr. Roger Morel, secretary of the English Apple Juice Producers' Association, and the enormous annual consumption of juices in Switzerland, Germany and the United States $(6,17$ and 100 million gallons respectively) were mentioned.

Mr. Christopher Norbury emphasized the urgent need for the introduction of a series of legal definitions for the strict standardization of all liquid fruit products.

Mr. Vernon L. S. Charley, in charge of the Fruit Products Section of the Station, gave a brief account of the various methods of manufacture and referred to the Long Ashton processes for apple juice and fruit syrups which had been in successful commercial use for three years. He laid special emphasis on the nutritional value of pure fruit juices and syrups,
\end{abstract}

pointing out that, though sucrose was used in the various processes, the final products as sold to the consumer contained only lævulose and glucose, which are the most easily assimilable forms of sugar. The mineral contents of these pure products was such that, despite the organic acids present, the high proportion of potassium and sodium oxides tended to build up an alkali reserve in the system. Although apple juices retain only a small proportion of the ascorbic acid (vitamin C) of the fresh fruit, blackcurrant syrup is a very rich source of this vitamin, quantities up to $100 \mathrm{mgm} . / 100 \mathrm{gm}$. of syrup having been found in syrups after twelve months' storage. Mr. Charley suggested that in times of national emergency canned black-currant syrup would assume a considerable importance in view of the possibility of the cessation or restriction of imports of fresh citrus fruits or juices. It was also pointed out that practically the whole of the nutritional value of fresh apples is retained by the processed juices.

In conclusion, details of the use of pure fruit juices and syrups for medicinal purposes were given. In Germany, inflammation of the lungs, diabetes, fevers and a number of other diseases were being treated with juices. In England, Mr. Charley referred to two series of cases in which children suffering from 'pink' disease, and adults and children being treated for hyperacidity with ulceration of the duodenum, had received great relief and in many cases had been cured by the use of apple juice ('pink' disease) and black-currant syrup (ulceration cases).

Working demonstrations enabled the visitors to observe the various cold and hot processes for the production of apple juice.

\section{Lord Rutherford: His Life and Influence on Chemistry}

$\mathrm{S}^{\mathrm{T}}$ IR HENRY TIZARD delivered the first Rutherford Memorial Lecture of the Chemical Society on March 29. He began by referring to Rutherford's early life at Cambridge, where he came in 1895 from New Zealand with an 1851 Exhibition. Continuing work on the detection of electrical waves which he had begun in New Zealand, Rutherford was able within a year to receive signals at a distance of halfa-mile; this work was described and demonstrated at the meeting of the British Association in 1896. The discovery, however, of $\mathrm{X}$-rays and of the radioactivity of uranium shortly after his arrival at Cambridge determined his life's work, and he became associated with J. J. Thomson in work on the ionization of gases by X-rays and on the electrical conduction caused by uranium radiation.

In 1898 , at the early age of twenty-seven years, Rutherford was appointed to the chair of physics at McGill University, Montreal, where he was joined by Soddy in investigations demonstrating that radioactivity is an atomic phenomenon accompanied by the continuous production of new types of matter with distinctive chemical properties. This work was predominantly chemical in character and led to
Rutherford receiving in 1908 the Nobel Prize in chemistry.

In 1907, Rutherford left Montreal for Manchester. By this time the general nature of radioactivity had been made clear, the disintegration theory was established, and the series of changes in uranium, thorium and actinium were understood. The happiest part of Rutherford's life was spent in Manchester, where he gathered around him a team of able and enthusiastic workers, and it was while there that the most dramatic event of his scientific career happened, namely, the discovery of the real nature of the atom. His work in Manchester was interrupted by the Great War, but at the end of 1918 he returned with renewed vigour to attack the structure of the nucleus, and within a year his efforts were rewarded, for he proved that nitrogen was destroyed by alpha particles and that hydrogen was a product. From that day to this there has been a continuous and almost bewildering addition to our knowledge of the structure of the nucleus.

Sir Henry Tizard said that Rutherford's influence on chemistry can be summarized in the following way. By his early work on the disintegration of 